\title{
Flexible Learning as an Instructional Modality in Environmental Science Course during COVID-19
}

\author{
Sylvester Tan Cortes ${ }^{1 *}$
}

${ }^{1}$ Cebu Technological University, PHILIPPINES

*Corresponding Author: sylvestertcortes@gmail.com

Citation: Cortes, S. T. (2020). Flexible Learning as an Instructional Modality in Environmental Science Course during COVID-19. Aquademia, 4(2), ep20024. https://doi.org/10.29333/aquademia/8444

\section{ARTICLE INFO}

Received: 9 Jun. 2020

Accepted: 12 Jul. 2020

\begin{abstract}
The novel coronavirus has forced the closure of schools and universities among countries with COVID-19 cases. Such move has reshaped the contour of education by shifting from face-to-face instruction to full online learning or flexible learning. Among the latter modalities of instruction, flexible learning (FL) appears to be the most practical because it lacks restriction of time, place, and pace of study. This study then aimed to explore the effectiveness of FL as an instructional modality in environmental science course following the action research method. In particular, perception on FL and environmental attitudes were evaluated at the end of the course. Results revealed that FL promotes authentic learning, active learning, and student autonomy. In terms of environmental attitudes, there maybe contrasting views in environmental issues presented to them but their views were anchored on their readings suggesting that the students read the course materials even without the presence of the teachers.
\end{abstract}

Keywords: action research, COVID-19, environmental attitude, flexible learning, reflective practice

\section{INTRODUCTION}

The costs of containing and treating the novel coronavirus are exorbitantly great, which even developed countries find it difficult to sustain (Haleem, Javaid, Vaishya, \& Deshmukh, 2020). In this regard, this infectious disease is not merely a serious global health concern because its impacts translate to socio-economic disruptions (Evans, 2020) and political crisis (Chakraborty \& Maity, 2020). In education, the impact is in form of closure of schools and universities (Viner et al., 2020), but it is likewise one of the intensive measures to reduce the spread of virus in a community by breaking key chains of transmission (Esposito \& Principi, 2020; Sahu, 2020). Such move has reshaped the contour of education by shifting from face-to-face to full online learning (Gewin, 2020). Although online learning is no longer a new norm of instruction in higher education, but previous reports reveal several challenges. These include but not limited to learners' readiness, lack of variation in pedagogy, and lack of empowerment in content development or merely teaching with predefined content (Kebritchi, Lipschuetz, \& Santiague, 2017). Further, many universities and colleges are not equipped with infrastructure that facilitates online teaching, and students do not have access to computer hardware and internet services (Sahu, 2020).
In the light of these concerns, flexible learning (FL) appears to be the most convenient instructional modality at the height of COVID-19. Although it requires internet-based tools such as virtual learning environment and learning management systems (Joan, 2013), flexible learning provides learners with increased authority about where, when, and how learning will occur (Shurville, O'Grady, \& Mayall, 2008). In other words, it is increasingly freed from the restrictions of place, time, and pace of study (Naidu, 2017). Further, most of the learning and teaching tasks in FL are not carried out online contrary to full online learning (Dhull \& Sakshi, 2017). However, science education has just been slower compared to other disciplines in adapting this genre because of concerns specific to the teaching of its disciplines and concerns about its effectiveness (Hallyburton \& Lunsford, 2013). In addition, there are also several challenges associated to it just as the case of full online learning such as challenges in learning styles, culture, pedagogy, technology, technical training, and time management (Islam, Beer, \& Slack, 2015). The advantage of FL setting rests on not requiring physical presence of both teacher and students, thus, a practical means of delivering instructions during COVID-19. It is in this regard that FL is suggested by the university administration as an alternate instructional modality in the existing crisis in education despite the challenges associated to it as reported by Islam et al. (2015). These challenges may still be resolved by careful planning, and 
proper use of technologies and learning theories, thus, eventually creating a space for reflective teaching practices in form of action research (AR).

While there is a great number of researches pertaining to the impact of the novel coronavirus in education (e.g. Sintema, 2020; Viner et al., 2020), studies exploring how to enhance flexible learning and resolve emerging issues and challenges associated to it are currently limited. The role of action research in resolving these issues cannot be discounted and is widely acknowledged in literature. Over the years, AR has gained popularity not only in solving social conflicts but even in resolving educational problems, and bridging the gap between educational research and classroom practice (Laudonia, Mamlok-Naaman, Abels, \& Eilks, 2017). Therefore, AR may be a practical tool to enhance or resolve the challenges specified by Hallyburton et al., (2013) and Islam et al. (2015) in FL settings particularly in environmental education. These can be realized through reflective teaching practice or AR which characterizes the cyclical process of innovation, research or inquiry, and reflection on the problem of focus. Previous study had already revealed that AR has significant roles in FL as evidenced by pedagogical modification and web-course design adjustments upon reflecting on issues and concerns associated with a web-based course (Lamaster \& Knop, 2004). These issues and concerns will likely reemerge in the use of FL as a mode of learning and teaching during this COVID-19, but reflective practice through AR will likely resolve these. Therefore, the aim of the present study is to explore the potentialities of flexible learning as an intervention in the current education crisis following the AR method. The modes of validating effectiveness of flexible learning are the perceptions of students towards it and their environmental attitude at the end of the course.

\section{Context}

This study was participated by a second-year environmental science class composed of 32 students in a state university in Central Visayas, Philippines. This university follows a semestral scheme where one semester is divided into four terms; preliminary, midterm, prefinal, and final term. Each semester normally has 54-hour allotment for a course divided into two alternate meetings a week. The first semester starts in August then ends in December while the second semester starts in January then ends in May. In particular, this study was conducted in second semester in the Academic Year 20192020. While action researches do not usually mention the year/s the studies was/were conducted except for their duration (e.g. Fernandez, 2017), the present study has to present this information because COVID-19 has caused the introduction of flexible learning as an alternate instructional modality due to closure of universities in the Philippines in March, 2020.. The use of FL ensured continuation of classes from midterm to final term of the semester even without physical contact between teachers and students in the university where the AR was conducted. However, its effectiveness is not well explored particularly in the teaching of environmental science course and several issues and concerns on its effectiveness have been raised. For this reason, there is a need to empirically validate its effectiveness by means of AR method in this particular university.

\section{METHODS}

This investigation followed an educational action research model introduced by Mertler (2017) which is a four-stage iterative or cyclical process. The stages include the following: planning, acting, developing, and reflecting. The planning stage involves preliminary investigation on the form, cause, or nature of the problem, and reviewing related literature. Both of these processes eventually inform the development of action research plan. The acting stage is composed of executing the plan and observing its results while the developing stage is when an action plan is developed. An action plan may contain description on the implementation of new educational practice, a plan to reflect on alternative strategies to resolving the problem, a plan containing what the researcher has learned, or a future plan the researcher intends to take in the next cycle of AR (Creswell, 2005; Johnson, 2008). Finally, the reflecting stage is composed of summarizing, sharing, and communicating results of the study, and reflecting on the entire AR process.

\section{Planning}

The development of this AR was grounded on the emergence of COVID-19. Upon closure of the university in March 2020 through Presidential Proclamation No. 929 declaring the Philippines under Enhanced Community Quarantine (ECQ), the university administration introduced flexible learning scheme as an alternate instructional modality to face-to-face learning. This is perhaps flexible learning is a centrally developed practice in the context of higher education institutions (Alexander, 2010). Eventually, this mandate has caused an adjustrment in the course syllabus particularly in the teaching-learning activities and assessment task. Teaching-learning activities had to be done either online or offline while assessment tasks were channeled online (see Table 1 for the modified course outline of the syllabus). In addition, an individual online consultation had to be added on the activities whenever individual concerns and questions were raised. Then, review on literature regarding the development of web-based FL course was conducted whereby the Features and Components Associated with E-Learning Environments introduced by Khan (2005) was selected as basis for the web-based course design. The framework suggests the following features of an effective e-learning environment, namely: ease of use, interactivity, multiple expertise, collaborative learning, authenticity, and learner-control. In this regard, a Google Classroom was set-up intended for the course. This free web-based platform or application is considered a class management tool in HEIs (Hemrungrote, Jakkaew, \& Assawaboonmee, 2017). Among of the features and functions of this platform are preparing classes, distributing tasks, providing real-time feedback from teachers, online reporting and interaction, sharing resources, etc. (Iftakhar, 2016). These features likely meet the criteria set by Khan (2005). The environmental science Google Classroom had six folders intended for the course syllabus, learning resources, learning tasks or assignments, rubrics, suggested readings, and survey questionnaires. Students may answer the tasks online or offline. Tasks answered offline were submitted via teacher's email or Facebook messenger. Finally, a group chat was 
Table 1. Environmental Science Course Outline

\begin{tabular}{|c|c|c|c|}
\hline Intended Learning Outcomes & Content & Teaching-Learning Activities & Assessment Task \\
\hline $\begin{array}{l}\text { Unit 1. Basic Environmental Concepts } \\
\text { Students are able to: } \\
\text { a. reflect on the roles of environmental ethics } \\
\text { towards any critical issue such as urbanization, } \\
\text { the spread of invasive species, impacts of climate } \\
\text { change, etc.; } \\
\text { b. explain climate change and pollution as forms of } \\
\text { market failure; and, } \\
\text { c. determine basic statistical concepts which are } \\
\text { relevant in the study of environmental science. }\end{array}$ & $\begin{array}{l}\text { 1. Scope of } \\
\text { Environmental } \\
\text { Sciences } \\
\text { 2. Environmental Ethics } \\
\text { 3. Environmental } \\
\text { Economics } \\
\text { 4. Environmental } \\
\text { Biostatistics }\end{array}$ & $\begin{array}{l}\text { Brainstorming on the the roles } \\
\text { of environmental ethics in the } \\
\text { context of critical problems } \\
\text { relating to the environment, } \\
\text { and on environmental } \\
\text { problems classified as market } \\
\text { failure. } \\
\text { Discussion of assigned } \\
\text { readings on biostatistics }\end{array}$ & $\begin{array}{l}\text { - } \text { Pre-assessment } \\
\text { - Group Activity: } \\
\text { Discussion and } \\
\text { presention of output } \\
\text { from brainstorming } \\
\text { - Treating hypothetical } \\
\text { data with basic } \\
\text { biostatistical tools } \\
\text { and presentation of } \\
\text { results }\end{array}$ \\
\hline $\begin{array}{l}\text { Unit 2. The Physical Environment } \\
\text { Students are able to: } \\
\text { a. write a summary and brief reflection on the value } \\
\text { of interrelationship between components of } \\
\text { ecosystem and physical environment. }\end{array}$ & $\begin{array}{l}\text { 1. The Lithosphere } \\
\text { 2. The Hydrosphere } \\
\text { 3. The Atmosphere }\end{array}$ & $\begin{array}{ll}\text { - } & \text { Book reading } \\
\text { - } & \text { Peer discussions } \\
\text { - } & \text { Online Consultation }\end{array}$ & $\begin{array}{l}\text { - } \text { Pre-assessment } \\
\text { - Summary Paper } \\
\text { - } \text { Reflection Paper }\end{array}$ \\
\hline $\begin{array}{l}\text { Unit 3. People and the Environment } \\
\text { Students are able to: } \\
\text { a. develop an appreciation of how functional units } \\
\text { of the natural environment are interrelated } \\
\text { b. explain the advantages and disadvanatages of a } \\
\text { growing population }\end{array}$ & $\begin{array}{l}\text { 1. Dynamics of Biological } \\
\text { Populations and } \\
\text { Human Population } \\
\text { 2. Properties of Biological } \\
\text { Communities } \\
\text { 3. Ecosystems } \\
\text { 4. Biomes }\end{array}$ & $\begin{array}{l}\text { - Annotation of assigned reading } \\
\text { on article relating to functional } \\
\text { units of ecosystem } \\
\text { - Watching BBC documentary on } \\
\text { growing population. } \\
\text { - Online Consultation }\end{array}$ & $\begin{array}{l}- \text { Pre-assessment } \\
\text { - Summary of } \\
\text { annotation } \\
\text { - Reflection from a } \\
\text { video documentary }\end{array}$ \\
\hline $\begin{array}{l}\text { Unit 4. Human Activities and the Environment } \\
\text { Students are able to: } \\
\text { a. create a model reflecting the sources of a } \\
\text { pollutant of your interest (e.g. plastics), along } \\
\text { with its transport, and environmental fate. } \\
\text { b. write a position paper on the extraction or use of } \\
\text { biotic and abiotic resources, and on the use of } \\
\text { nuclear energy as a source of electrical power. }\end{array}$ & $\begin{array}{l}\text { 1. Pollutions of the } \\
\text { Physical Environment } \\
\text { 2. Degradation \& } \\
\text { Depletion of Natural } \\
\text { Resources }\end{array}$ & $\begin{array}{l}\text { - Independent reading of articles } \\
\text { relating to the pollutant of } \\
\text { interest } \\
\text { - Watching video documentaries } \\
\text { (e.g. poaching in West } \\
\text { Philippine Sea) } \\
\text { - Online Consultation }\end{array}$ & 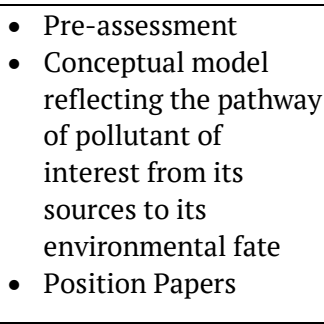 \\
\hline $\begin{array}{l}\text { Unit 5. Environmental Conservation and } \\
\text { Restoration } \\
\text { Students are able to: } \\
\text { a. review international environmental agreements } \\
\text { or treaties and Philippine Environmental Laws } \\
\text { b. evaluate their attitudes, behaviours, and values } \\
\text { towards the environment }\end{array}$ & $\begin{array}{l}\text { 1. Restoration Ecology } \\
\text { 2. Green Architecture } \\
\text { 3. International } \\
\text { Environmental } \\
\text { Treaties and Philippine } \\
\text { Environmental Laws } \\
\text { 4. Sustainable } \\
\text { Development }\end{array}$ & 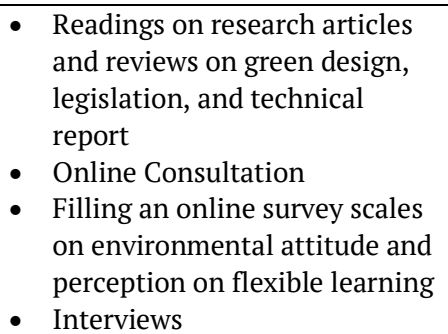 & $\begin{array}{l}\text { Pre-assessment } \\
\text { - Critical Essay on the } \\
\text { role of restoration } \\
\text { ecologists in engaging } \\
\text { with values, policy } \\
\text { making, and science } \\
\text { - Critical essay on the } \\
\text { relevance of Kyoto } \\
\text { Protocol up to date }\end{array}$ \\
\hline
\end{tabular}

created in Facebook messenger intended also for the course. Teacher's instructions were relayed there, and eventually served too as platform for class discussion.

\section{Acting}

This AR is a mixed methods research which employed sequential explanatory design (QUAN $\rightarrow$ qual). It is characterized by collection and analysis of quantitative data in the primary phase then qualitative data in the succeeding phase. In this design, data collection in two phases are separated but connected as qualitative results are used to explain the quantitative results (Creswell, 2009). For the quantitative method, a one-shot case study was employed. This is characterized by exposure of an experimental group to a treatment in the passage of time and culminates at measure or an observation. Although this design has received considerable criticisms because of apparent or virtual absence of internal or external validity (Campbell \& Stanley, 1963), the present study does not have baseline information on students' perception on flexible learning and their environmental attitude prior to the study. Thus, one-shot case study was appropriate and a practical option. For qualitative method, multiple case studies were used to provide in-depth description and support the quantitative findings and to execute polyangulation of data.

There were two scales used to gather quantitative data, namely: Distance Education Learning Environments Survey (DELES) (Walker \& Fraser, 2005) and Environmental Attitude Scale (EAS) (Berberoglu \& Tosunoglu, 1995). DELES was used to assess perception of HEISs students in distance learning settings including flexible learning set-up. It has 34 items distributed into six scales: (1) instructor support; (2) student interaction and collaboration; (3) personal relevance; (4) authentic learning; (5) active learning; and (6) student autonomy. The cumulative variance explained by these six scales is $67.15 \%$ while the reliability coefficient of these six scales using Cronbach's alpha as a measure of internal consistency ranges from 0.75 to 0.95 . Each item in all scales was rated as always, often, sometimes, seldom, and never by the students. Meanwhile, EAS was used to assess 


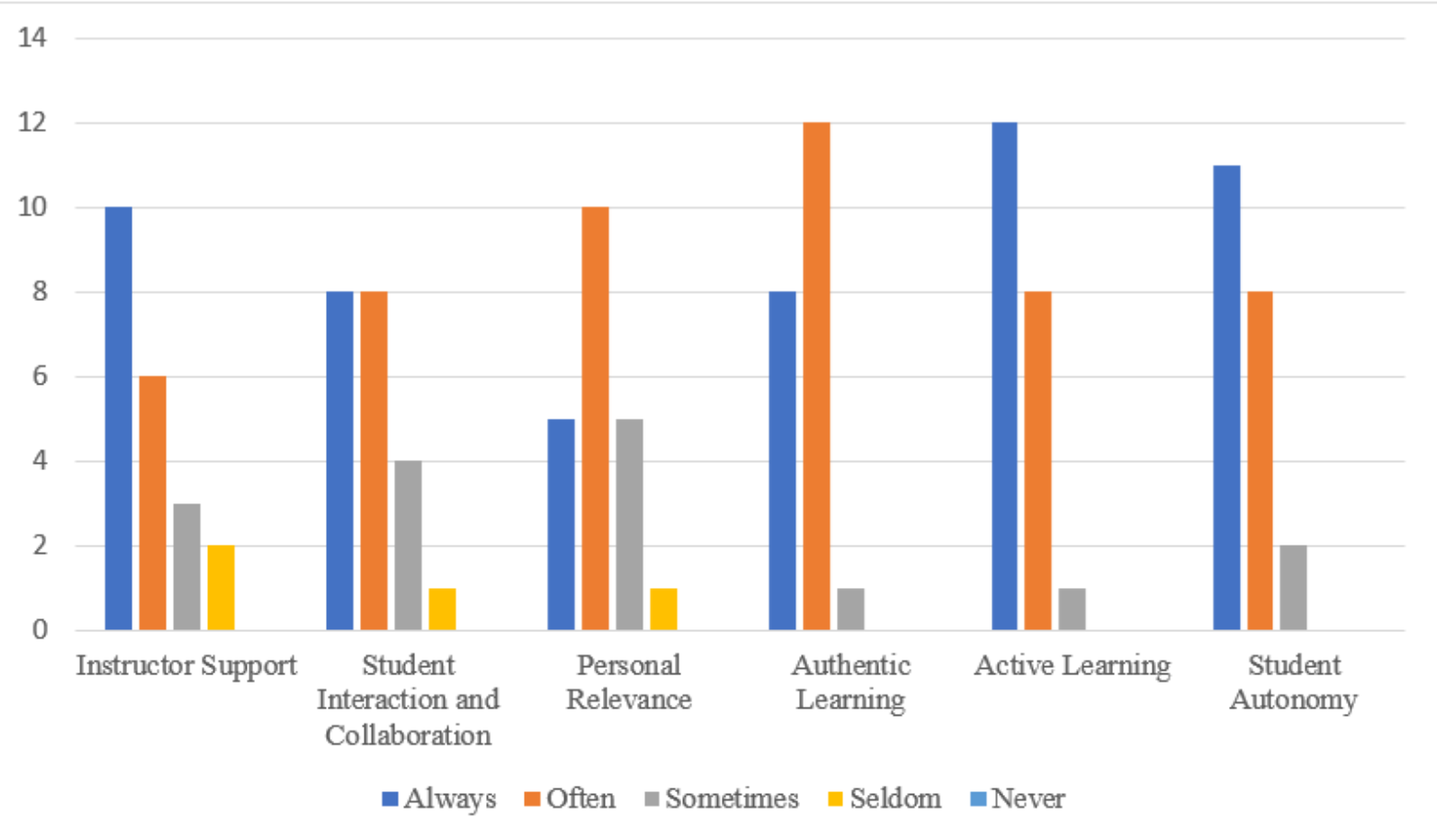

Figure 1. Distribution of students level of perception on flexible learning in environmental science

environmental attitudes of the students. It has 18 items distributed in four scales: (1) population growth, (2) environmental problems, (3) nuclear energy, and (4) energy conservation. These four scales accounted for $54.1 \%$ of the variance in item responses while the Cronbach's alpha reliability estimate of the entire scale was 0.75 . Each item in all scales was rated as strongly agree, agree, undecided, disagree, and strongly disagree. The results in DELES and EAS are graphed reflecting frequency distribution of students per level of perception and level of attitude per factor, respectively. There were 21 students who participated in these survey questionnaires. The mean and standard deviation per fators are also reported to indicate its over all rating. For the qualitave method, two students were interviewed about their experiences in flexible learning setting and were referred with pseudonyms to protect their identities, namely: Anna and Vince. Meanwhile, there were four students who participated in the interview relating to environmental issues. They were assigned with the following pseudonyms: Vie, Gri, Rid, and Han. The researcher used open-ended interview protocol as a guide during the interview proper. Subsequently, narrative accounts from interviews were used to support on the quantitative results per factor of the two scales.

\section{Students' perceptions on the use of flexible learning setting in environmental science}

The perceptions of students on flexible learning as applied in environmental science course are presented in Figure 1. These perceptions pertain to the six factors evaluated by DELES scale, namely: instructor support, student interaction and collaboration, personal relevance, authentic learning, active learning, and student autonomy. In instructor support ( $M=4.05, S D=0.76)$, there is a wide distribution of students' pereceptions ranging from seldom to always. On an average, their overall perception in this factor centers in the often level.
This indicates that students satisfactorily gained online support on an FL set-up whereby they felt that the online environment encouraged them to participate and inqure, and their questions and concerns were promptly addressed by the teacher. This result was affirmed by Anna who noted that "The instructions were well-defined and our concerns were promptly addressed." The development of a group chat (GC) intended for the course on a social media platform likely explained her statement. The GC allowed the students to interact and receive real-time feedback on their questions and concerns from their teacher. Their conversation are archived as a thread and all members of the GC can view the previous and recent messages. However, there were several students who criticized this mode of instructional deliverty. In particular, Vince explained, "I still prefer face-to-face classes over tasks being done online or independently because sometimes all our concerns are impossible to attend to and I am ashamed of posting messages in the GC or sending it personally to the teacher." This statement was affirmed by several individuals too in class. A survey in US explained that instructional approaches and support may actually differ between online and face-to-face classes (Zweig \& Stafford, 2016). These factors will likely explain students success in FL settings because some preferred face-to-face over online class and vice versa. Further, there are teachers utilizing online environments to relay learning tasks or conduct classes but lack training in this area, and this is true for the teacher handling this environmental science course. In effect, students' perception in instructor support in FL setting differed from one to another.

With respect to student interaction and collaboration $(M=$ 3.88, $S D=0.71$ ) in an FL set-up, responses are still spread from seldom to always. The average adjectival rating in this factor is still often which indicates that they were often sharing their works with others in the class, sharing information, and working in groups. However, Anna had a contrasting view with 
this result. She stated, “Working with my classmates through online was not easy because not all of us have gadgets and internet access." This statement was probably speaking regarding the situation of the majority of the students in class. Some of them were using mobile phones to communicate, download learning materials, research, and upload course requirements instead of a desktop or laptop computer. On the same note, Vince explained, "I worked alone now because it is hard to share and discuss information and ideas online with my classmates." $\mathrm{He}$ added that if he do so via the GC, he would only receive irrelevant responses. These experiences are alarming as student-student interactions should have been valuable learning experiences where they intellectually interact with the learning contents. Their interaction will likely result to deep understanding or changes in cognitive structures within their minds. However, their experiences in an FL set-up with regards to student-student interactions are challenging and less.

In the third factor which is on personal relevance $(M=3.91$, $S D=0.63$ ), responses still range from seldom to always but almost half perceived that the topics they were learning in the course are often relevant to them. This relevance pertains to the topics being relatable and applicable to their degree program, lives, and activities outside the class. Anna expressed that some of the suggested readings are useful in the degree program they are currently enrolled in.

\section{Researcher : How relevant are our learning tasks and} suggested readings?

Anna : Our topics in environmental science were very relatable and relevant especially in our program. As a student specializing in drafting, I get to read and understand the concepts of green architecture in designing and building houses and other infrastructures. The readings allowed me to identify eco-friendly construction materials and practices.

This is likely similar with the reponse of Vince. He stated, "Most of the materials we were reading were relevant and I was learning." He added that he was able to identify practices which could minimize the introduction of pollutants in the environment by way of reading. However, there were terms which he encountered that were jargon to him. He said, "It was time-consuming searching those terms and was consuming my internet data. If the teacher was there, he could have explained those terms for us in a practical manner." These responses that the tasks and readings were relevant and relatable can be attributed to how the course syllabus was designed. Although the course is not classified in their prospectus or curriculum as a major subject but rather a cognate, it was ensured that learning tasks and resources used were constructively aligned with the desired outcome of their degree program, Bachelor of Science in Industrial Technology - Drafting, such as the inclusion of green design.

In terms of authentic learning $(M=4.08, S D=0.62)$, their perceptions are within sometimes, often, and always. There was a great number of students $(n=12)$ who perceived that they often were involved into an authentic learning while on an FL set-up. This is because students were dealing with real facts, information, examples, cases, and topics in the course which were integrated in the learning materials provided to them (e.g. empirical studies, review papers, and video clips). In addition, tasks were designed from these materials in a situated learning approach where they analyse, synthesize and evaluate those materials. These tasks are known to promote authentic (Herrington \& Herrington, 2008) and active learning (Khan, Egbue, Palkie, \& Madden, 2017). This also explained why Vince raised a concern previously that the tasks were "time-consuming" while Anna described it as "challenging." Meanwhile, in terms of active learning $(M=4.37, S D=0.47)$, responses fall majority in the two highest levels of perception, always $(n=12)$ and often $(n=8)$. It is a good indication that most of the students were exploring their strategies of learning, seeking their own answers, and solving their own problem while on an FL set-up. This instructional modality according to Anna also required them do the following learning activities, namely: (a) doing further research beside the course materials given, (b) taking down notes of important ideas, and (c) reading in advance. Vince also added (d) exercising time management and (e) working independently. In other words, doing those learning strategies promote active learning within themselves. However, Vince also presented criticisms despite recognizing FL a practical means of developing active learning. He stated that that he could barely approach his classmates in this set-up because everybody was independently working on their own, and complying tasks online demand time, effort, and resources. This led him to a conclusion that "The idea of flexible learning is good but is never easy."

Finally, students' perception on their autonomy $(M=4.30$, $S D=0.60$ ) in an FL set-up are majority within always and often. The fact that the mean adjectival rating is equivalent to always in this factor, students were demonstrating capacity for autonomy in their own learning. In other words, they were were making decisions, controlling, and playing important roles in their learning. It is characterized by taking responsibility to plan, reflect and evaluate their own learning. Vince described the way he learned as "free" and "unrestricted". However, he associated himself to a Gold Fish in a small aquarium with this learning set-up whereby learning was limited. He said, "I would rather be in a big aquarium swimming and learning with my classmates because chances of learning is more." He further explained that the pressure with face-to-face classes before encouraged him to suceed more in the course. He stated, "I can see the progress of my classmates and that pushed me to do well too." On tha same note, Anna emphaized that there is less discussion and interaction with FL setting although tasks may be done at their convenient times. She concluded that if course materials are discussed, they would gain deeper understanding on the concepts.

\section{Students' environmental attitudes after flexible learning setting}

Students' environmental attitudes towards population growth, environmental problems, nuclear energy, and energy conservation after learning in an FL set-up are presented in Figure 2. In population growth $(M=3.40, S D=0.52)$, the mean level of agreement is undecided indicating a conflict of views whether population should be decreased or increased, and if the carrying capacity of the Earth's resources are still proportional to the global population. This also indicates that 


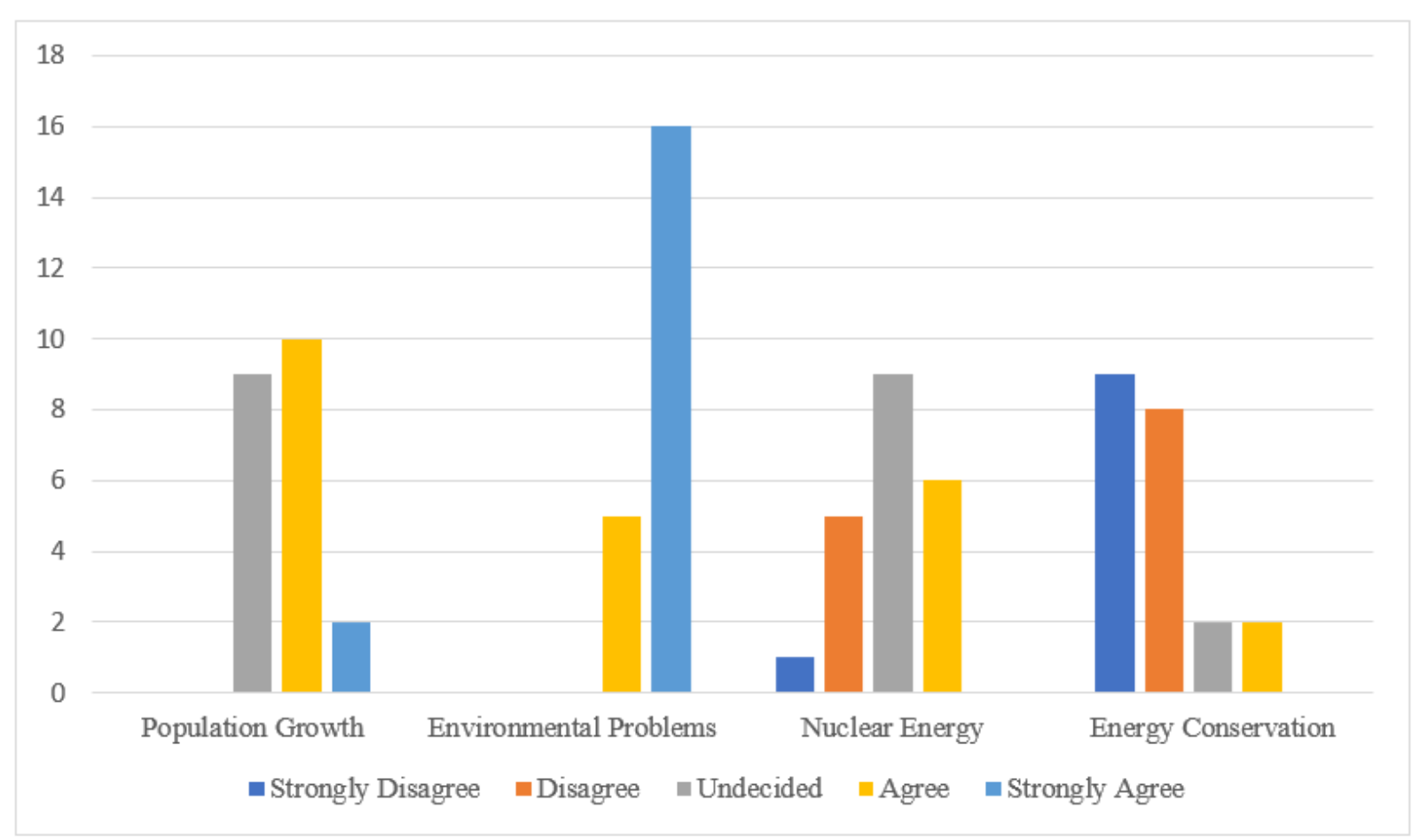

Figure 2. Distribution of students level of environmental attitudes

the students were undecided on their stand towards population growth and birth control. However, it does not mean also that they do not have sound perspectives towards population growth. For example, Vie has the following perspective.

\section{"Part of me says it is fine and part of says it is not. Looking on the good aspect of population growth as read in an article about environmental economics, a country does not experience labour shortage as compared to developed countries with small population and are recruiting migrants. The negative impact however lies on the question whether the carrying capacity of our resources will be enough to sustain the needs of a growing population. In addition, we are sent in this world to multiply."}

This perspective does not indicate that Vie was undecided because of the lack of knowledge. Rather, her attitude towards the issue was influenced by her economic perspective, environmental resources, and religion. Whereas, Gri strongly opposed the idea of population growth because of the limited resources we have of which some are even non-renewable. She also added that the government cannot attend the needs of everyone with the growing population. These perspectives about population growth are grounded on their learnings from the articles given to them indicating that they were reading the course materials.

With respect to environmental problems $(M=4.59, S D=$ $0.35)$, majority strongly agreed that this should be given top priority. This also indicates a strong agreement or willingness to work with organizations which thrust are on safeguarding the welfare of the environment. In an interview, Gri said, "I think environmental problems are everybody's concern and we do not need to discuss anymore why." She added that, "I am even delighted that the ozone layer is healing naturally due to community quarantine where movements and activities of humans are limited." Her latter statement reflects of why she agreed that environmental problems should be dealt with, otherwise the environment will work that for us. Meanwhile, in the case of Rid, one learning activity had reoriented her perspective towards environmental problems. From his readings, he came up with an illustration of the drivers and fate of water pollutants (see Figure 3). He realized that most of these pollutants were of anthropogenic in origin before deposited in to the bodies of water. In this regard, he realized that the causes of environmental problems are primarily us, thus, he strongly agreed also that resolving environmental problems should be a priority by us not only by the government.

In terms of students' attitudes towards nuclear energy ( $M$ $=2.95, S D=0.69$ ), their responses were spread from strongly disagree to agree. Its mean adjectival rating falls to undecided. This indicates that students have varying attitudes towards the use of nuclear energy as a power source. For example, Vie who remained undecided just as her stand towards population growth, explained,

\footnotetext{
"I am undecided again because I have this in mind that with nuclear energy, I think our problem on energy gap will be resolved because of the large energy output which nuclear power plant produces contrary to renewable energy sources such as the wind and hydroelectric. However, this power source is not practical among countries which are earthquake prone areas. This will likely result to nuclear disaster such as that in Japan in 2011."
}

According to Vie, this persective was grounded on two articles which she read, one on the recommendation on the use of nuclear power plant while the other presents the 


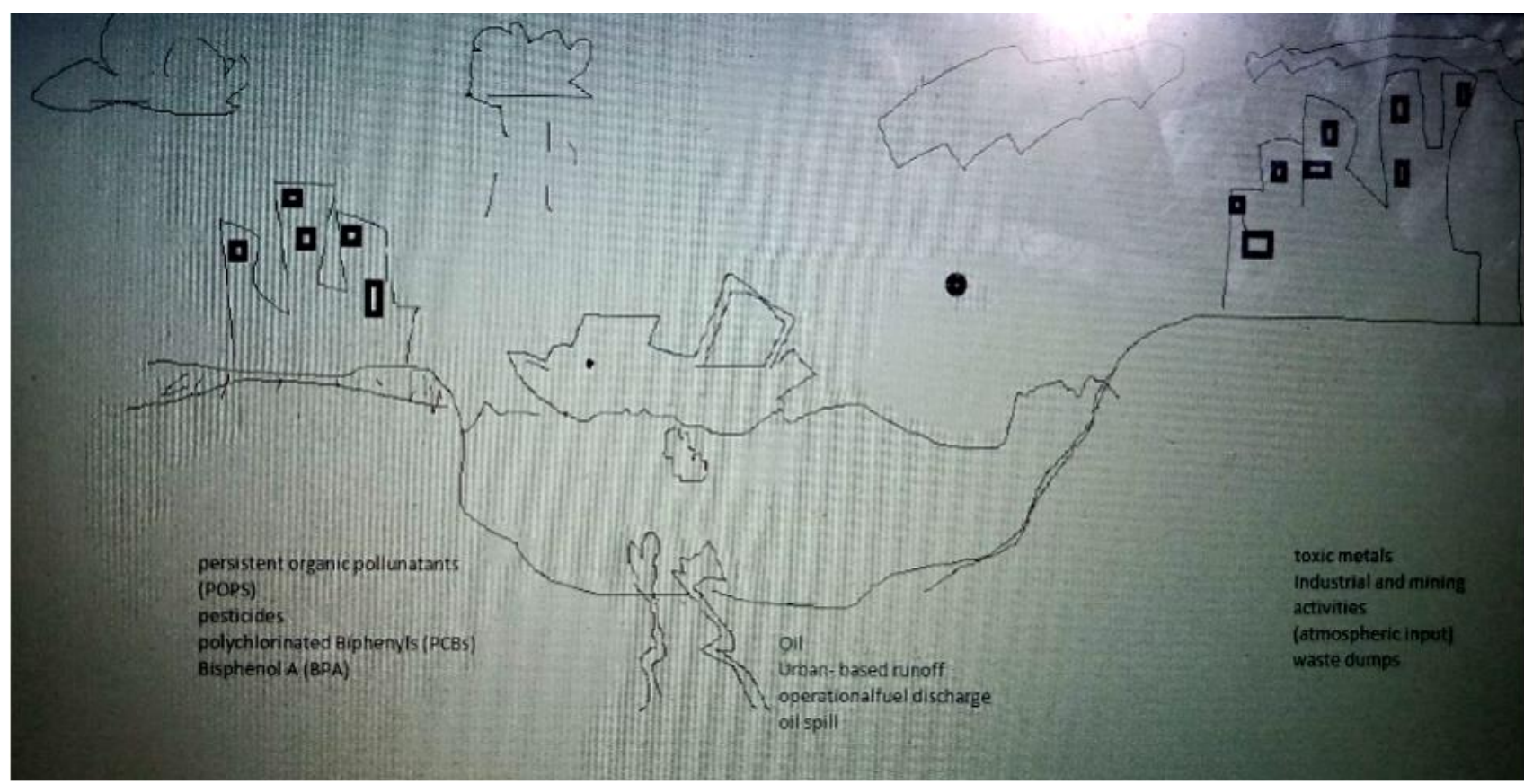

Figure 3. Sample of students' work illustrating his understanding from his readings on the anthropogenic origins of pollutants which will likely affect a physical environment (i.e. water)

disadvantages of this power source. She was unable to decide if she would agree or disgree on the use of this power source because both points were of equal weights. In the case of Hann, she strongly disagreed on the use of nuclear energy as a power source particularly here in the Philippines. She stated,

"It is execrable and unacceptable to build nuclear energy here in the Philippines because it effectuates harm to the people, environment and to all those living organisms. According to scientific study I read, it is also dangerous to one's health in which it increases risk for cancer among people who live near the nuclear power plants.”

Hann remained firm that the use of renewable energy is the best option over nuclear energy. This perspective was opposed by Gri because her readings suggest that fatalities in nuclear disaster are relatively smaller as compared to yearly deaths in coal and gas industries. In addition, she explained that renewable energy resources are not economically viable to support the energy needs of large industries. However, Gri acknowledged that nuclear energy are associated with negative impacts which is why she did not also strongly agree that it should be used but rather an intermittent option. These contrasting views or attitudes of the students towards nuclear energy suggest that their statements were grounded on what they read regardless if they agree or do not agree on the issue. This further manifests that these students were reading the course materials provided to them even without the presence of the teachers.

Finally, in terms of students' attitudes towards energy conservation $(M=2.00, S D=0.83)$, responses are distributed from agree to strongly disagree. Nonetheless, this does not indicate that the students were against energy conservation because items in this factor were negaively stated. An example of negatively stated item is this "I don't like trying to save some water." The presence of a contraction "don't" makes the item negative. The mean adjectival rating in this factor is disagree indicating that they were against the following practices: not saving electricity and not cutting down water consumption. There were only four students who partly agreed and were undecided about energy conservation because they cannot afford to get away from their usual lifestyle such as having multiple mobile phones which require charging the batteries according to them. The rest agreed that energy should be conserved particularly in the Philippines which is relying majority on coal, a non-renewable resource.

\section{Action Plan}

The use of flexible learning as an instructional modality in environmental science course during COVID-19 required appropriate technology to channel and archive the course readings, teaching-learning activities, assessment tasks, and other relevant course materials. In this regard, Google Classroom served as the learning management system (LMS) where the aforecited course materials were uploaded and archived by the teachers, and where the students download them. However, this LMS was insufficient in the context of this particular group of students because some were not opening their emails or the Google Classroom time to time. Thus, a group chat on a messaging app (i.e. Facebook Messenger) had to be created as an auxiliary LMS because students usually open this anytime of the day. Some of the materials were even uploaded here if the file size does not exceed the allowed value.

With these LMSs, instructions were still transmitted and learning still took place. However, there were several criticisms regarding their use. These criticisms were particularly on their inability to cope with the demands of time and resources. Because the materials were uploaded online, the students have to buy internet data, borrow computer, and sacrifice using their mobile phones to comply with the tasks assigned. Furthermore, the students criticized the tasks 
contained in the LMS in which they identified those tasks as time-consuming and very challenging. However, those tasks were really designed in a fashion that they have to analyse, synthesize and evaluate most if not all of the learning materials. Those are part of the adjustments made in the teaching-learning activities and tasks in an FL set-up, a method called situated learning approach, to ensure authentic and active learning were not compromised even without the presence of teachers. In fact, there were 20 students from 21 who agreed that they were always or often actively and authentically learning in the course.

Another criticism students had raised was on online consultation, some of them were not satisfied because some of their concerns were not attended by the teacher even with the messaging app. The app was even used as a platform to discuss irrelevant topics or topics not necessarily related to the course by the students. This is despite the clear rule that the app was intended for consultation. Another problem was that some of them were not confident to interact in the group chat and were reluctant to message directly the teacher atlhough some did. In other words, they only rely to the instructions embedded in the course materials. This is particularly true because there were several outputs which desired outcomes on particular tasks did not reflect or were incorrect. The lack of clarifications on the instruction likely explains such. Likewise, if the students were complaining on this mode of interaction, the teacher was dealing the same problem particularly on online consultation. Messages popped-up time to time and some were really not attended as much as the teacher wanted.

In the future action research, the same LMS may be used but several adjustments have to made based on the problems identified in the present study. Other option may be using another LMS to compare which is more efficient for a flexible learning set-up such Moodle, Google Suite for Education, or Edmodo. However, there is a need for technical training first to teachers who will be using these online LMSs for them to be acquainted with the system or platform. Some of the features we are looking may be in the LMS we are using but we failed to explore it because of our reluctance to do so. Finally, there is a need to add another domain (e.g. environmental knowledge) as mode of evaluating effectiveness of FL in environmental course. While environmental attitude evaluates students' affective domain, environmental knowledge evaluates the cognitive domain or students' understanding of the things and objects in the environment. Also, an evaluation of the LMS used is suggested. Specifically, those features and components associated with e-Learning environments introduced by Khan (2005)

\section{Reflecting or Concluding Remarks}

Flexible learning setting in environmental science course as revealed by the present study promotes authentic learning, active learning, and student autonomy. Meanwhile, perceptions whether this instructional modality is effective in terms of instructor support, student interaction and collaboration, and promoting personal relevance were dispersed. In other words, future studies may take into account of how to further develop or promote these factors in an FL setting. It can be concluded also that because FL promotes student autonomy, students were regulated to study and perform the tasks independently. Their efforts in studying translate to their varying perspectives and attitudes towards four environmental issues which were grounded on their readings of course materials.

\section{REFERENCES}

Alexander, S. (2010). Flexible Learning in Higher Education. International Encyclopedia of Education, 441-447. https://doi.org/10.1016/B978-0-08-044894-7.00868-X

Berberoglu, G., \& Tosunoglu, C. (1995). Exploratory and Confirmatory Factor Analyses of an Environmental Attitude Scale (EAS) for Turkish University Students. The Journal of Environmental Education, 26(3), 40-43. https://doi.org/10.1080/00958964.1995.9941444

Campbell, D. T., \& Stanley, J. C. (1963). Experimental and quasi-experimental designs for research. Boston: Houghton Mifflin.

Chakraborty, I., \& Maity, P. (2020). COVID-19 outbreak: Migration, effects on society, global environment and prevention. Science of The Total Environment, 728, 138882. https://doi.org/10.1016/j.scitotenv.2020.138882

Creswell, J. W. (2005). Educational Research: Planning, coducting, and evaluating quantitative and qualitative research. Upper Saddle River, NJ: Merrill/Prentice Hall.

Creswell, J. W. (2009). Research design: Qualitative, quantitative, and mixed methods approaches (3rd Edition ed.). United States of America: SAGE Publications, Inc.

Dhull, I., \& Sakshi, M. (2017). Online Learning. International Education \& Research Journal, 3(8), 32-34.

Esposito, S., \& Principi, N. (2020). School Closure During the Coronavirus Disease 2019 (COVID-19) Pandemic: An Effective Intervention at the Global Level? JAMA Pediatrics. Published online May 13, 2020. https://doi.org/10.1001/ jamapediatrics.2020.1892

Evans, O. (2020). Socio-economic impacts of novel coronavirus: The policy solutions. BizEcons Quarterly, 7, 312.

Fernandez, F. B. (2017). Action research in the physics classroom: the impact of authentic, inquiry based learning or instruction on the learning of thermal physics. AsiaPacific Science Education, 3, 3. https://doi.org/10.1186/ s41029-017-0014-z

Gewin, V. (2020). Five tips for moving teaching online as COVID-19 takes hold. Nature. Retrieved from https://www.nature.com/articles/d41586-020-00896-7

Haleem, A., Javaid, M., Vaishya, R., \& Deshmukh, S. G. (2020). Areas of academic research with the impact of COVID-19. The American Journal of Emergency Medicine, 38(2020), 1524-1526. https://doi.org/10.1016/j.ajem.2020.04.022

Hallyburton, C. L., \& Lunsford, E. (2013). Challenges and Opportunities for Learning Biology in Distance-Based Settings. Bioscene, 39(1), 27-33. 
Hemrungrote, S., Jakkaew, P., \& Assawaboonmee, S. (2017). Deployment of Google Classroom to Enhance SDL Cognitive Skills: A Case Study of Introduction to Information Technology Course. International Conference on Digital Arts, Media and Technology (ICDAMT), Chiang Mai, Thailand. https://doi.org/10.1109/ICDAMT.2017. 7904961

Herrington, A., \& Herrington, J. (2008). What is an Authentic Learning Environment? Authentic Learning Environments in Higher Education. https://doi.org/10.4018/978-1-59140594-8.ch001

Iftakhar, S. (2016). Google Classroom; What work and how? Journal of Education and Social Sciences, 3, 12-18.

Islam, N., Beer, M., \& Slack, F. (2015). E-Learning Challenges Faced by Academics in Higher Education: A Literature Review. Journal of Education and Training Studies, 3(5), 102112. https://doi.org/10.11114/jets.v3i5.947

Joan, D. R. (2013). Flexible Learning as New Learning Design in Classroom Process to Promote Quality Education. $i$ manager's Journal on School Educational Technology, 9(1), 37-42.

Johnson, A. P. (2008). A Short Guide to Action Research. Boston: Allyn \& Bacon.

Kebritchi, M., Lipschuetz, A., \& Santiague, L. (2017). Issues and Challenges for Teaching Successful Online Courses in Higher Education: A Literature Review. Journal of Educational Technology, 46(1), 4-29. https://doi.org/ $10.1177 / 0047239516661713$

Khan, A., Egbue, O., Palkie, B., \& Madden, J. (2017). Active Learning: Engaging Students To Maximize Learning In An Online Course. The Electronic Journal of e-Learning, 15(2), 107-115.

Khan, B. H. (2005). Learning Features in an Open, Flexible, and Distributed Environment. Association for the Advancement of Computing In Education Journal, 13(2), 137-153.

Lamaster, K. J., \& Knop, N. (2004). Improving Web-based Instruction: using action research to enhance distance learning instruction. Educational Action Research, 12(3), 387-412. https://doi.org/10.1080/09650790400200257
Laudonia, I., Mamlok-Naaman, R., Abels, S., \& Eilks, I. (2017). Action research in science education - an analytical review of the literature. Educational Action Research, 26(3), 480495. https://doi.org/10.1080/09650792.2017.1358198

Mertler, C. A. (2017). Action research: Improving schools and empowering educators ( 5 th ed.). Thousand Oaks, California: SAGE Publications, Inc.

Naidu, S. (Ed.). (2017). How flexible is flexible learning, who is to decide and what are its implications? Distance Education, 38(3), 269-272. https://doi.org/10.1080/01587919.2017. 1371831

Sahu, P. K. (2020). Closure of Universities Due to Coronavirus Disease 2019 (COVID-19): Impact on Education and Mental Health of Students and Academic Staff. Cureus, 12(4), e7541. https://doi.org/10.7759/cureus.7541

Shurville, S., O’Grady, T., \& Mayall, P. (2008). Educational and Institutional Flexibility of Australian Educational Software. Campus-Wide Information Systems, 5(2), 74-84. https://doi.org/10.1108/10650740810866576

Sintema, E. J. (2020). Effect of COVID-19 on the Performance of Grade 12 Students: Implications for STEM Education. Eurasia Journal of Mathematics, Science and Technology Education, 16(7), em1851. https://doi.org/ 10.29333/ejmste/7893

Viner, R. M., Russell, S. J., Croker, H., Packer, J., Ward, J., Stansfield, C., \& Booy, R. (2020). School closure and management practices during coronavirus outbreaks including COVID-19: a rapid systematic review. Lancet Child Adolescent Health, 4, 397-404. https://doi.org/10.1016/S2352-4642(20)30095-X

Walker, S. L., \& Fraser, B. J. (2005). Development and Validation of an Instrument for Assessing Distance Education Learning Environments in Higher Education: The Distance Education Learning Environments Survey (DELES). Learning Environments Research, 8, 289-308. https://doi.org/10.1007/s10984-005-1568-3

Zweig, J. S., \& Stafford, E. T. (2016). Training for Online Teachers to Support Student Success: Themes from a Survey Administered to Teachers in Four Online Learning Programs. Journal of Online Learning Research, 2(4), 399418. 